\title{
Vitamin D status and its determinants during autumn in children at northern latitudes: a cross-sectional analysis from the optimal well-being, development and health for Danish children through a healthy New Nordic Diet (OPUS) School Meal Study
}

\author{
Rikke A. Petersen ${ }^{1}{ }^{*}$, Camilla T. Damsgaard ${ }^{1}$, Stine-Mathilde Dalskov ${ }^{1}$, Louise B. Sørensen ${ }^{1}$,
} Mads F. Hjorth ${ }^{1}$, Christian Ritz ${ }^{1}$, Louise Kjølbæk ${ }^{1}$, Rikke Andersen ${ }^{2}$, Inge Tetens ${ }^{2}$, Henrik Krarup ${ }^{3}$, Arne Astrup ${ }^{1}$, Kim F. Michaelsen ${ }^{1}$ and Christian Mølgaard ${ }^{1}$

${ }^{1}$ Department of Nutrition, Exercise and Sports, Faculty of Science, University of Copenhagen, Rolighedsvej 26,1958

Frederiksberg C, Denmark

${ }^{2}$ Division of Nutrition, The National Food Institute, Technical University of Denmark, Mørkhøj Bygade 19, 2860 Søborg, Denmark

${ }^{3}$ Department of Clinical Biochemistry, Section of Molecular Diagnostics, Aalborg University Hospital, Hobrovej 18-22, 9000 Aalborg, Denmark

(Submitted 5 June 2015 - Final revision received 2 October 2015 - Accepted 2 October 2015 - First published online 13 November 2015)

\section{Abstract}

Sufficient summer/autumn vitamin D status appears important to mitigate winter nadirs at northern latitudes. We conducted a cross-sectional study to evaluate autumn vitamin D status and its determinants in 782 Danish 8-11-year-old children $\left(55^{\circ} \mathrm{N}\right)$ using baseline data from the Optimal well-being, development and health for Danish children through a healthy New Nordic Diet (OPUS) School Meal Study, a large randomised controlled trial. Blood samples and demographic and behavioural data, including 7-d dietary recordings, objectively measured physical activity, and time spent outdoors during school hours, were collected during September-November. Mean serum 25-hydroxyvitamin D (25(OH)D) was $60 \cdot 8(\mathrm{sD} 18.7) \mathrm{nmol} / \mathrm{l}$. Serum $25(\mathrm{OH}) \mathrm{D}$ levels $\leq 50 \mathrm{nmol} / 1$ were found in $28.4 \%$ of the children and $2.4 \% \mathrm{had}$ concentrations $<25 \mathrm{nmol} / \mathrm{l}$. Upon multivariate adjustment, increasing age (per year) $(\beta-2 \cdot 9 ; 95 \% \mathrm{CI}-5 \cdot 1,-0.7 \mathrm{nmol} / \mathrm{l})$, female sex $(\beta-3 \cdot 3 ; 95 \% \mathrm{CI}-5 \cdot 9,-0 \cdot 7 \mathrm{nmol} / \mathrm{l})$, sampling in October $(\beta-5 \cdot 2 ; 95 \% \mathrm{CI}-10 \cdot 1,-0 \cdot 4 \mathrm{nmol} / \mathrm{l})$ and November $(\beta-13 \cdot 3 ; 95 \% \mathrm{CI}-17 \cdot 7,-9 \cdot 1)$, and non-white ethnicity $(\beta-5 \cdot 7 ; 95 \% \mathrm{CI}-11 \cdot 1$, $-0.3 \mathrm{nmol} / \mathrm{l}$ ) were negatively associated with $25(\mathrm{OH}) \mathrm{D}$ (all $P<0 \cdot 05)$. Likewise, immigrant/descendant background was negatively associated with $25(\mathrm{OH}) \mathrm{D}$, particularly in females $(\beta-16.3 ; 95 \% \mathrm{CI}-21.9,-10.7)(P<0.001)\left(P_{\text {interaction }}=0.003\right)$. Moderate-to-vigorous physical activity (MVPA) $(\mathrm{min} / \mathrm{d})(\beta 0.06 ; 95 \% \mathrm{CI} 0 \cdot 01,0 \cdot 12)$, outdoor walking during school hours (min/week) $(\beta 0.4 ; 95 \% \mathrm{CI} 0 \cdot 1,0 \cdot 6)$ and intake of vitamin D-containing supplements $\geq 3 \mathrm{~d}$ /week $(\beta 8 \cdot 7 ; 95 \%$ CI 6.4, 11.0) were positively associated with $25(\mathrm{OH}) \mathrm{D}$ (all $P<0 \cdot 05$ ). The high proportion of children with vitamin D status below the recommended sufficiency level of $50 \mathrm{nmol} / 1$ raises concern as levels expectedly drop further during winter months. Frequent intake of vitamin D supplements was strongly associated with status. MVPA and outdoor activity during school hours should be investigated further in interventions to improve autumn vitamin D status in children at northern latitudes.

Key words: Vitamin D: Children: Northern latitudes: Determinants

Determinants of vitamin D status are complex to evaluate but require attention as vitamin $\mathrm{D}$ deficiency has been found to occur commonly among, for example, healthy European children and adolescents ${ }^{(1)}$, and as vitamin D facilitates intestinal Ca absorption and optimal bone health ${ }^{(2,3)}$. Vitamin D plays a particularly crucial role during childhood growth stages, when accumulation of skeletal Ca increases vastly ${ }^{(4)}$. The vitamin D metabolite 25-hydroxyvitamin D $(25(\mathrm{OH}) \mathrm{D})$ has a half-life of
2-3 weeks, and currently serves as a suitable marker of vitamin D status $^{(5)}$. Although different cut-off levels are advocated ${ }^{(6)}$, the European Society for Paediatric Gastroenterology, Hepatology and Nutrition (ESPGHAN) has recently re-established the recommendation of a $25(\mathrm{OH}) \mathrm{D}$ concentration $>50 \mathrm{nmol} / \mathrm{l}(20 \mathrm{ng} / \mathrm{ml})$ to indicate sufficiency ${ }^{(1)}$. Severe vitamin $\mathrm{D}$ deficiency during childhood, established by ESPGHAN as 25(OH)D concentrations $<25 \mathrm{nmol} / \mathrm{l}^{(1)}$, may lead to painful joints, muscle/bone disorders

Abbreviations: DHA, docosahexanoic acid; EI, energy intake; MVPA, moderate-to-vigorous physical activity; OPUS, optimal well-being, development and health for Danish children through a healthy New Nordic Diet.

* Corresponding author: R. A. Petersen, email riap@ucl.dk 
and overt rickets ${ }^{(7,8)}$. In addition, vitamin D status has been inversely associated with extra-skeletal conditions such as type 1 diabetes, CVD and certain cancers ${ }^{(9,10)}$. Under conditions of regular skin exposure to sunlight, dietary vitamin D intake is estimated to contribute about $10 \%$ of human vitamin D requirements $^{(5)}$, and only few foods such as egg yolks and fatty fish are naturally rich in vitamin $\mathrm{D}^{(11)}$. The remaining $90 \%$ is estimated to originate from the production that occurs in the skin upon exposure to UVB waves in sunlight ${ }^{(5)}$. Indeed, sun exposure of hands, arms and face in non-skin-reddening doses 2-3 times/week has been suggested to satisfy the vitamin D requirement of most people ${ }^{(12)}$. Yet, decreased solar intensity makes cutaneous production unattainable from November through February at latitudes of $52^{\circ} \mathrm{N}$ and above ${ }^{(13-15)}$. Children living in northern latitude countries are therefore thought to be at risk of vitamin D deficiency, particularly in winter/early spring. Indeed, sufficient summer/autumn vitamin D status appears important to mitigate such winter nadirs in these children ${ }^{(16)}$. It is therefore of great relevance to identify behavioural factors of summer/autumn vitamin D status in children at these latitudes.

In addition to seasonal UVB fluctuations, the extent of skin pigmentation has been shown to modify the cutaneous vitamin $\mathrm{D}$ production so that dark-skinned children generally require more sun exposure compared with fair-skinned peers to produce the same amount of vitamin $\mathrm{D}^{(17-19)}$. Indeed, previous studies on vitamin $\mathrm{D}$ in Scandinavian children have consistently found vitamin D concentrations to be lower in winter than in summer, and among immigrant or dark-skinned children, and they have shown a positive association between vitamin $\mathrm{D}$ status and intake of vitamin D supplements ${ }^{(16,20-25)}$. Other observed, but less consistent, correlations with vitamin D status in Scandinavian children have included dietary vitamin $\mathrm{D}$ intake ${ }^{(24)}$, sun habits ${ }^{(16)}$ and, inversely, $\mathrm{BMI}^{(22,24)}$. Yet, previous studies have had relatively small sample sizes ${ }^{(16,20-25)}$, and most have included only specific groups such as adolescent girls or immigrant children ${ }^{(16,20,23,25)}$. The aim of the present cross-sectional study was to evaluate autumn vitamin D status and identify demographic and behavioural determinants hereof in a large and highly representative sample of children in Denmark $\left(55^{\circ} \mathrm{N}\right)$. The study was based on baseline data from the Optimal well-being, development and health for Danish children through a healthy New Nordic Diet (OPUS) School Meal Study and included 782 third and fourth graders from nine schools in Denmark. The study provided innovative and previously unexamined vitamin D determinants at this latitude and time of year, including the role of being outdoors during school hours.

\section{Methods \\ Study design and subjects}

The OPUS School Meal Study was a large cluster-randomised controlled cross-over trial that aimed to assess the impact of providing school meals based on the New Nordic Diet on dietary intake and nutrient status, growth, early disease risk markers, well-being and absence from school, cognitive function, food waste and cost, as well as social features in third- and fourth-grade children. The design of the OPUS School Meal Study has been described in detail elsewhere ${ }^{(26)}$. Participants were recruited from May to October 2011. Briefly, initial contact was established with thirty-nine schools, of which nine were included. Inclusion criteria for the schools in the OPUS Study were (a) location in the eastern part of Denmark (Zealand and Lolland-Falster), (b) a total of four or more classes at third and fourth grade, (c) suitable kitchen facilities available for food production during school hours and (d) a high motivation for participation as determined by the study team. As more than nine schools were eligible for participation, logistical matters were also taken into consideration. Moreover, the aim was that $\geq 50 \%$ of the schools should belong to municipalities where (a) the income was below the national mean for families with children and (b) the percentage of households in which the adults had lower secondary education ( $\leq 10$ years) was above the national mean for families with children, as defined by Statistics Denmark ${ }^{(27)}$. Ultimately, three of the nine $(33 \%)$ included schools fulfilled these criteria. Written information about the study was sent to the families of all third- and fourth-grade children at the nine participating schools, and the families were invited to an information meeting. In order to recruit families of various socio-economic and ethnic backgrounds, we held several information meetings at each school, sent out several reminders, and had translators present at meetings when relevant. Exclusion criteria for the invited third- and fourth-grade children were (a) diseases or conditions that might obstruct the measurements or put the child at risk by eating the intervention school meals, or (b) concomitant participation in other scientific studies that involved radiation or blood samples. We obtained written informed consent for participation from all custody holders of 834 children, corresponding to $82 \%$ of the 1021 invited children. The enrolment percentage at the nine schools ranged from 60 to $89 \%$. The schools were located in eight separate municipalities and the included children came from rural as well as urban areas.

\section{Ethics statement}

This study was conducted according to the guidelines laid down in the Declaration of Helsinki and all procedures involving human subjects were approved by the Committees on Biomedical Research Ethics for the Capital Region of Denmark (H-1-2010-124); the study was registered in the database www.clinicaltrials.gov (no. NCT 01577277). Written informed consent was obtained from custody holders of all subjects.

\section{Socio-demographic characteristics, screen time and puberty stage}

Information on demographic and socio-economic characteristics was collected at baseline by an in-depth 2 -h personal interview with the child and parents. The highest education level attained in the household was used to categorise parental educational level into lower secondary education ( $\leq 10$ years), upper secondary education, vocational education, short higher education, a Bachelor's degree or equivalent, or a Master's degree or higher ( $\geq 17$ years). The birth countries of parents and grandparents were used to categorise the children as immigrant/descendants or not. Children were categorised into 'immigrants/descendants' if all 
grandparents and $\geq 1$ parent were born outside Denmark. Though not identical, this classification was based on the definitions of immigrants and descendants used by Statistics Denmark ${ }^{(28)}$.

Parents estimated the child's daily 'screen time' during the previous week - that is, watching television or using the computer and game consoles - and the registered min/weekday was applied for this variable. Finally, puberty status was self-evaluated by child and parents on the basis of breast development in girls and pubic hair in boys (Tanner stages) as validated by Morris \& Udry $^{(29)}$. Registrations were dichotomised into a variable indicating entered puberty ( $\geq$ Tanner stage 2 ) (yes/no).

\section{Registration of dietary intake, physical activity and outdoor activity during school hours}

Before the clinical measurements, the children, aided by their parents, recorded their daily intake of food and beverages for 7 consecutive days using a Web-based Dietary Assessment Software for Children developed specifically for children aged 8-11 years ${ }^{(30)}$. The software was validated in the OPUS School Meal Pilot Study, although not specifically for vitamin D intake $^{(31,32)}$. Intake data were processed by a General Intake Estimation System, originally developed for the Danish National Survey of Diet and Physical Activity 2003-2008 (Division of Nutrition, The National Food Institute, Technical University of Denmark, Denmark) ${ }^{(33)}$. Energy intake (EI) relative to estimated BMR was evaluated following the equations of Henry ${ }^{(34)}$, and energy under-reporters (EI:BMR $\leq 1.05)$ and over-reporters (EI:BMR $\geq 2.28)^{(35)}$ were excluded from the dietary variables, as were children who registered their diet for $<4 \mathrm{~d}$. Dietary intake did not include the intake from supplements.

The intake of dietary supplements was registered separately in the dietary recordings and the daily intake of vitamin D-containing supplements, including multivitamins, was summarised in the current study. Supplement intake was applied without excluding children who recorded for $<4 \mathrm{~d}$ and without excluding energy over- and under-reporters.

To measure physical activity, the children were asked to wear an accelerometer (ActiGraph GT3X+ Tri-Axis Accelerometer Monitor) in an elastic belt tightly at the right hip for the same seven days and eight nights as the dietary recordings, and to remove it only during water activities - that is, showering or swimming. Analyses of the physical activity data are described in detail elsewhere $^{(36)}$. Derived variables included time spent sedentarily (0-100 counts per minute $(\mathrm{cpm})$ ) and moderate-to-vigorous physical activity (MVPA) $(\geq 2296 \mathrm{cpm})$. Also, the families recorded the child's amount of bicycling during weekdays.

School settings and policies on outdoor activity differed between the nine schools. From a questionnaire to the principal of each school we obtained information on whether the children were obligated by school policy to spend all recesses outdoors (obligatory outdoor recesses), and approximately how many minutes per week the children spent outside during school hours in walking between classrooms and other school facilities (outdoor walks between classrooms). Outdoor walks between classrooms indicated a necessary non-voluntary outdoor walking activity certain to take place for the child to get between classrooms. This variable depended on the school architecture as some schools were made up of several buildings scattered around an area, whereas other schools were made up of one entire building that therefore did not require any outdoor walking to get between classrooms during school hours.

\section{Anthropometry and ethnicity}

Anthropometric measurements were conducted during morning hours at each school, after the child had been fasting since midnight, had emptied the bladder and was wearing only light clothing. Height was measured in $\mathrm{cm}$ to the nearest one decimal using a transportable stadiometer (CMS Weighing Equipment Ltd). Height was derived as the mean of three consecutive measurements with the child in standing position, holding his head in the Frankfurter plane. Body weight was measured in $\mathrm{kg}$ to the nearest one decimal using a digital scale (BWB $800 \mathrm{~S}$; Tanita). BMI was calculated as body weight $(\mathrm{kg}) /$ height $(\mathrm{m})^{2}$, and sex- and age-adjusted $z$-scores for BMI were calculated using WHO AnthroPlus software ${ }^{(37)}$. The OPUS School Meal Study also included dual-energy X-ray absorptiometry (DXA) scans of each child conducted at the same occasion as the blood sampling. In relation to the DXA scan the ethnicity of the child was originally recorded by an investigator based on physical presence and statement of the child. Ethnicity was recorded according to the terminology of the Lunar Prodigy Pro ${ }^{\mathrm{TM}}$ (GE Medical Systems) DXA scanner with EnCore ${ }^{\mathrm{TM}}$ software - that is, Caucasian, Asian, African, Latin or Other. These recordings were applied for ethnicity categorisation in the current study - that is, children recorded as Caucasian were named white ethnicity. These also included children from Turkey, the Middle East, Pakistan and India. Because of small numbers in the four non-Caucasian groups (non-Caucasian $n$ 41), we dichotomised ethnicity recordings into a variable indicating white ethnicity (yes/no).

\section{Blood markers of vitamin D status and fatty fish intake}

Blood samples were collected in August/September ( $n$ 311), October ( $n$ 146) or November ( $n$ 325) 2011 at the same time as the anthropometric measures. As August samples were few ( $n$ 21), and were collected only on 30 and 31 August, these samples were combined with the September samples. Local anaesthetic patches were offered to the children to reduce discomfort, and blood was sampled by means of venepuncture after an overnight fast from all children at one school before moving on to the next school. Serum was separated by centrifuging collected blood at $2500 \mathrm{~g}$ at $4^{\circ} \mathrm{C}$ for $10 \mathrm{~min}$ after $30 \mathrm{~min}$ at room temperature. Serum was then stored at $-80^{\circ} \mathrm{C}$ for later vitamin D analysis. Heparinised whole blood was mixed with $0.1 \%$ butylated hydroxytoluene (Sigma-Aldrich) in ethanol $\left(0.1 \mathrm{ml} / \mathrm{ml}\right.$ blood) and stored at $-80^{\circ} \mathrm{C}$ for later analysis of fatty acid composition. As a measure of vitamin D status, $25(\mathrm{OH}) \mathrm{D}$ concentrations (25-hydroxy-vitamin $\quad \mathrm{D}_{2}+\mathrm{D}_{3} \quad$ (DTOT25)) were assessed in serum by automatic ChemiLuminescence ImmunoAssay technology on DiaSorin LIAISON (DiaSorin AB) at the Department of Clinical Biochemistry, Aalborg University Hospital, Aalborg, Denmark, a laboratory partaking in the vitamin D External Quality Assessment Scheme (DEQAS) ${ }^{(38)}$. Before analysis, serum was defrosted at room temperature for half 
an hour and centrifuged at $4000 \mathrm{rpm}$ for $3 \mathrm{~min}$. Concentrations are presented in $\mathrm{nmol} / \mathrm{l}(1 \mathrm{nmol} / \mathrm{l}=0.4006 \mathrm{ng} / \mathrm{ml})$, and the lowest detection limit was $10 \mathrm{nmol} / \mathrm{l}$. Intra-assay $\mathrm{CV}$ for $25(\mathrm{OH}) \mathrm{D}$ was $7.6 \%$, whereas inter-assay CV for $25(\mathrm{OH}) \mathrm{D}$ was $5.4 \%$. As a biomarker of fatty fish intake, EPA + docosahexanoic acid (DHA) status was assessed in whole blood by means of high-throughput GC. Fatty acid methyl esters were prepared from whole-blood samples by direct trans-esterification with convectional heat as previously described ${ }^{(39,40)}$. The amount of EPA+DHA is presented as $\mathrm{w} / \mathrm{w} \%$ of the total whole-blood fatty acids. Intra- and inter-assay CV for EPA wt $\%$ were 1.2 and $4.5 \%$, whereas intra- and inter-assay CV for DHA wt $\%$ were 2.4 and $6.4 \%$, respectively.

\section{Statistical analyses}

The statistical analyses were carried out using Stata (version 12.1; StataCorp LP). Significance was established at $P<0 \cdot 05$. Betweengroup differences in population characteristics were evaluated using the two-sample $t$ test (unequal variances), the Wilcoxon and Mann-Whitney test (for non-normally distributed outcomes) and the $\chi^{2}$ or Fisher's exact test for categorical outcome variables. Linear mixed effects models were used to identify factors associated with serum $25(\mathrm{OH}) \mathrm{D}$ concentrations (the outcome). Model checking was based on visual inspection of residual and normal probability plots. For all mixed models, school, grade and class were included as random effects to account for the dependency structures imposed by the hierarchical design. A priori, we considered month of sampling and intake of vitamin D supplements to be wellestablished determinants of vitamin D status to be included in all models. Initially, a basic demographic linear mixed model was constructed with outcome and random effects as specified above, and with month of sampling, intake of vitamin D-containing dietary supplements (in proportion to days of dietary recordings - i.e. days with intake of vitamin D-containing supplements/total number of days of dietary recordings) and all demographic variables included as fixed effects: that is, white ethnicity (yes/no), immigrant/ descendant background (yes/no), age, sex, entered puberty (i.e. Tanner stage $\geq 2$ (yes/no)) and parental education level. Subsequently, interactions between sex and puberty, sex and immigrant/descendant background, sex and ethnicity, and sex and month of sampling were included one by one in this demographic model and tested by likelihood ratio tests. Significant interactions were retained in the model. In the next step, each behavioural variable identified (see below) was assessed one by one through inclusion in the above demographic model. Because of the behavioural complexity of vitamin D sources, this approach was applied to increase the transparency of the contribution of each of the behavioural variables distinct from the effects of the remaining explanatory variables in the model, and to address potential collinearity between variables. The behavioural variables included were as follows: MVPA ( $\mathrm{min} / \mathrm{d})$, sedentary time $(\mathrm{min} / \mathrm{d})$, 'screen time' (min/weekday), bicycling ( $\mathrm{min} /$ weekday), BMI-for-age $z$-score, outdoor walking between classrooms during school hours ( $\mathrm{min} /$ week), obligatory outdoor recesses during school hours (yes/no), whole-blood EPA + DHA (wt \%) as a biomarker of fatty fish intake, intake of dietary vitamin $\mathrm{D}(\mu \mathrm{g} / \mathrm{d})$ and intake of dietary $\mathrm{Ca}(\mathrm{mg} / \mathrm{d})$. Eventually, to evaluate the strength of the associations found for each single behavioural variable, all significant behavioural variables were simultaneously included in the demographic model.

In addition, to further elaborate on the association between serum 25(OH)D concentration and frequency of vitamin D-containing supplement intake, we conducted a more detailed sub-analysis with a categorical vitamin D supplement variable including only children who recorded their dietary intake for all $7 \mathrm{~d}$ (days with intake of vitamin D-containing supplements/7 d). This categorical supplement variable was then evaluated in the demographic model.

\section{Results}

\section{Subject characteristics}

Of the 834 children enrolled in the OPUS School Meal Study, eleven children withdrew from the study before the clinical measurements at baseline, seven were ill or on holiday on the day of sampling, and thirty-four children failed to deliver a blood sample or had a sample with insufficient blood volume for $25(\mathrm{OH}) \mathrm{D}$ analysis. Ultimately, baseline samples for $25(\mathrm{OH})$ $\mathrm{D}$ analysis were successfully collected from 782 children. These $n 782$ children comprised the study population for evaluation of the vitamin D status in the present study and had an age range of 8-11 years. Boys were older, spent more time with MVPA, spent more screen time, and had higher serum 25(OH)D concentrations compared with girls. More girls than boys had entered puberty (Table 1). Overall, $62 \%$ of the children were obligated to go outdoors during all recesses of their school day. This applied for more third graders (89\%) than fourth graders $(60 \%)(P<0 \cdot 001)$. On average, children spent a mean of $8 \mathrm{~min} /$ week (range 0-30) walking outdoors between classrooms and these numbers were higher for fourth graders $(9.5 \mathrm{~min} /$ week; range $0-20)$ than for third graders $(6.5 \mathrm{~min} /$ week; range $0-30)$ $(P<0 \cdot 001)$.

A total of sixty-four children ( $8 \%$ ) were excluded from analyses with dietary variables because of being under-reporters, fourteen (2\%) because of being over-reporters, and twenty-three (3\%) for recording their diet for $<4 \mathrm{~d}$. Of the remaining sample, thirty-nine (6\%) children consumed $\geq 7.5 \mu \mathrm{g}$ of dietary vitamin $\mathrm{D} / \mathrm{d}$ (the official recommended intake at the time of the study ${ }^{(43)}$ ), whereas thirty children ( $4 \%$ ) consumed $\geq 10 \mu \mathrm{g} / \mathrm{d}$ (the new official recommendation $\left.{ }^{(44)}\right), 172$ (25\%) had an intake between 2.5 and $7.5 \mu \mathrm{g} / \mathrm{d}$, and 470 (69\%) consumed $\leq 2.5 \mu \mathrm{g} / \mathrm{d}$. Boys had higher daily intakes of energy, protein (energy \%), dietary vitamin D, Ca and milk (Table 2). Yet, because of their higher EI, the higher daily intake of dietary vitamin D in boys compared with girls was not retained when dietary vitamin D intake was calculated as $\mu \mathrm{g} / \mathrm{MJ}$. The same occurred with the intake of milk and dietary Ca.

An overall ninety children (11.5\%) were categorised as immigrants/descendants; $44 \%$ of them were girls and $91 \%$ originated from a single foreign country only. Turkish roots were predominant along with roots in Pakistan and the former Yugoslavian Republic, accounting for 30, 18 and $17 \%$ of the immigrant/descendant children, respectively. The majority ( $80 \%$ ) of the immigrant/descendant children were white; that is, only eighteen of the forty-one non-white children in the study had an immigrant/descendant background. Valid dietary recordings were 
Table 1. Characteristics of the study population according to sex

(Mean values and standard deviations; medians and 25th-75th percentile tested for sex differences)

\begin{tabular}{|c|c|c|c|c|c|c|}
\hline & \multirow[b]{2}{*}{$n$} & \multicolumn{2}{|c|}{ Girls } & \multicolumn{2}{|c|}{ Boys } & \multirow[b]{2}{*}{$P$} \\
\hline & & Mean & SD & Mean & SD & \\
\hline$\%$ & 782 & \multicolumn{2}{|c|}{$47 \cdot 7$} & \multicolumn{2}{|c|}{$52 \cdot 3$} & \\
\hline Age (years) & 782 & 9.9 & 0.7 & $10 \cdot 1$ & 0.6 & $<0.001$ \\
\hline Height $(\mathrm{cm})$ & 782 & $142 \cdot 3$ & $7 \cdot 1$ & $142 \cdot 9$ & $7 \cdot 1$ & 0.24 \\
\hline Weight (kg) & 781 & & & & & 0.26 \\
\hline Median & & \multirow{2}{*}{\multicolumn{2}{|c|}{$\begin{array}{c}33.9 \\
29.7-38.5\end{array}$}} & \multirow{2}{*}{\multicolumn{2}{|c|}{$\begin{array}{c}34.3 \\
30.2-39.8\end{array}$}} & \\
\hline 25th-75th percentile & & & & & & \\
\hline BMI-for-age $z$-scores & 781 & 0.08 & 1.04 & 0.21 & $1 \cdot 10$ & 0.08 \\
\hline Weight status $(\%, \text { uw/nw/ow/ob) })^{*}$ & 781 & \multicolumn{2}{|c|}{$11 / 74 / 13 / 2$} & \multicolumn{2}{|c|}{$9 / 78 / 11 / 2$} & 0.50 \\
\hline Puberty stage $(\%, 1 / 2 / 3 / 4 / 5) \dagger$ & 757 & \multicolumn{2}{|c|}{$53 / 36 / 10 / 0 \cdot 3 / 0$} & \multicolumn{2}{|c|}{$76 / 20 / 3 / 0 / 0 \cdot 3$} & $<0.001$ \\
\hline White ethnicity (\%) & 779 & \multirow{2}{*}{\multicolumn{2}{|c|}{$\begin{array}{l}95 \cdot 2 \\
10.7\end{array}$}} & \multicolumn{2}{|c|}{$94 \cdot 4$} & 0.61 \\
\hline Immigrants/descendants (\%)‡ & 782 & & & & & 0.51 \\
\hline Parental education $(\%, \mathrm{~A} / \mathrm{B} / \mathrm{C} / \mathrm{D} / \mathrm{E} / \mathrm{F}) \S$ & 779 & \multicolumn{2}{|c|}{$6 / 4 / 33 / 10 / 28 / 19$} & \multicolumn{2}{|c|}{$5 / 3 / 31 / 10 / 28 / 23$} & 0.76 \\
\hline Sedentary activity $(\mathrm{min} / \mathrm{d}) \|$ & 756 & 470 & 61 & 475 & 66 & 0.25 \\
\hline Moderate-to-vigorous physical activity $(\mathrm{min} / \mathrm{d}) \boldsymbol{\uparrow}$ & 756 & & & & & $<0.001$ \\
\hline Median & & \multirow{2}{*}{\multicolumn{2}{|c|}{$\begin{array}{c}37 \\
26-48\end{array}$}} & \multicolumn{2}{|c|}{57} & \\
\hline 25th-75th percentile & & & & \multicolumn{2}{|c|}{$39-73$} & \\
\hline Bicycling on weekdays (min/d) & 624 & \multicolumn{2}{|c|}{$26-48$} & & & 0.24 \\
\hline Median & & \multicolumn{2}{|c|}{11} & \multicolumn{2}{|c|}{12} & \\
\hline 25th-75th percentile & & \multicolumn{2}{|c|}{$4-18$} & \multicolumn{2}{|c|}{$6-19$} & \\
\hline Screen time on weekdays $(\min / \mathrm{d})^{\star *}$ & 750 & & & & & $<0.001$ \\
\hline Median & & \multicolumn{2}{|c|}{$\begin{array}{c}120 \\
75-155\end{array}$} & \multicolumn{2}{|c|}{130} & \\
\hline 25th-75th percentile & & \multicolumn{2}{|c|}{$75-155$} & \multicolumn{2}{|c|}{$90-185$} & \\
\hline Obligatory outdoor recesses during school hours (\%, no/yes) & 782 & \multirow{2}{*}{\multicolumn{2}{|c|}{$36 \cdot 2 / 63 \cdot 8$}} & \multicolumn{2}{|c|}{$40 \cdot 1 / 59 \cdot 9$} & 0.26 \\
\hline Outdoor walking between classrooms at school ( $\mathrm{min} /$ week) & 782 & & & & & 0.51 \\
\hline Median & & & & & & \\
\hline 25th-75th percentile & & & & & & \\
\hline Month of blood sampling (\%, August-September/October/November) & 782 & & & & & 0.47 \\
\hline Serum 25-hydroxyvitamin D (nmol/l) & 782 & $58 \cdot 4$ & $18 \cdot 1$ & $62 \cdot 9$ & $19 \cdot 0$ & $<0.001$ \\
\hline Whole-blood EPA + DHA (wt\%) & 772 & 3.6 & 1.0 & 3.6 & 1.0 & 0.68 \\
\hline Supplements intake $(\%, 0 / 1 / 2 / 3 / 4 / 5 / 6 / 7 \mathrm{~d} /$ week $) \dagger \dagger$ & 693 & $45 / 8 / 5$ & $/ 8 / 17$ & $50 / 6 / 4$ & /8/16 & 0.80 \\
\hline
\end{tabular}

uw, Underweight; nw, normal weight; ow, overweight; ob, obese; A, Slower secondary education; B, upper secondary education; C, vocational education; D, short higher education;

$\mathrm{E}$, Bachelor's degree or equivalent; $\mathrm{F}$, $\geq$ Master's degree.

* Based on age- and sex-specific cut-offs defined to pass through BMI of $18.5,25$ and $30 \mathrm{~kg} / \mathrm{m}^{2}$ at age 18 years, as described by Cole et al. ${ }^{(41,42)}$.

$\dagger$ Tanner stages as validated by Morris \& Udry ${ }^{(29)}$.

$\ddagger$ Determined as 4 grandparents $+\geq 1$ parent born outside Denmark, motivated by definitions of immigrants and descendants used by Statistics Denmark ${ }^{(28)}$.

$\S$ Based on the highest parental education level in the household.

॥ $0-100 \mathrm{cpm}$, measured by ActiGraph.

I $\geq 2296 \mathrm{cpm}$, measured by ActiGraph.

** The amount of time the child spends on TV, game consoles, computer, etc., during weekdays, estimated by the parents.

†† Days per $7 \mathrm{~d}$-registration with intake of a vitamin D-containing supplement, also including multivitamins.

Table 2. Dietary intake of the study population according to sex

(Mean values and standard deviations; medians and 25th-75th percentile tested for sex differences)

\begin{tabular}{|c|c|c|c|c|c|}
\hline & \multicolumn{2}{|c|}{ Girls } & \multicolumn{2}{|c|}{ Boys } & \multirow[b]{2}{*}{$P$} \\
\hline & Mean & SD & Mean & SD & \\
\hline Subjects $(n)$ & \multicolumn{2}{|c|}{322} & \multicolumn{2}{|r|}{359} & \\
\hline Energy $(\mathrm{kJ} / \mathrm{d})$ & 7210 & 1174 & 8290 & 1406 & $<0.001$ \\
\hline Protein (E\%) & 15 & 2 & 16 & 2 & 0.016 \\
\hline Fat $(\mathrm{E} \%)$ & 32 & 4 & 32 & 4 & 0.32 \\
\hline \multirow[t]{2}{*}{ Carbohydrates (E\%) } & 53 & 5 & 52 & 5 & 0.06 \\
\hline & Median & 25th-75th percentile & Median & 25th-75th percentile & \\
\hline Dietary vitamin $D(\mu \mathrm{g} / \mathrm{d})^{\star}$ & $1 \cdot 7$ & $1 \cdot 3-2 \cdot 6$ & $2 \cdot 0$ & $1.5-2.9$ & 0.002 \\
\hline Dietary Ca $(\mathrm{mg} / \mathrm{d})^{*}$ & 843 & 684-1006 & 953 & $796-1180$ & $<0.001$ \\
\hline Fish (total) (g/d) & 12 & $0-27$ & 12 & $0-30$ & 0.48 \\
\hline Fatty fish $(\mathrm{g} / \mathrm{d})$ & 3 & $0-14$ & 0 & $0-13$ & 0.24 \\
\hline $\operatorname{Egg}(g / d)$ & 14 & $10-22$ & 14 & $9-24$ & 0.53 \\
\hline Milk (g/d) & 329 & $224-443$ & 371 & $264-512$ & 0.002 \\
\hline
\end{tabular}

* Not including intake from supplements. 
handed in by fifty-eight (64\%) of the immigrant/descendant children; this was fewer than the $90 \%$ in the non-immigrant group $(P<0 \cdot 001)$. Immigrant/descendant children recorded a $571 \mathrm{~kJ}$ lower EI per day $(P=0.006)$, an approximately $0.6 \mu \mathrm{g}$ lower intake of dietary vitamin $\mathrm{D} / \mathrm{d}(P=0.03)$ and an approximately $122 \mathrm{mg}$ lower intake of dietary $\mathrm{Ca} / \mathrm{d}(P=0.001)$ compared with nonimmigrant children. However, the differences in dietary vitamin $\mathrm{D}$ and $\mathrm{Ca}$ intake disappeared when calculated as $\mu \mathrm{g} / \mathrm{MJ}$ and $\mathrm{mg} / \mathrm{MJ}$, respectively. No children carried veils or other cultural or religious attires.

\section{Serum 25-hydroxyvitamin D concentrations}

Mean serum $25(\mathrm{OH}) \mathrm{D}$ concentration for the total population ( $n$ 782) was $60 \cdot 8$ (sD 18.7) nmol/l (range 15.2-132 nmol/l). Serum $25(\mathrm{OH}) \mathrm{D}$ concentrations $\leq 50 \mathrm{nmol} / \mathrm{l}$ were found in $222(28.4 \%)$ of the children, of whom nineteen $(2.4 \%)$ had concentrations $<25 \mathrm{nmol} / \mathrm{l}$ (Fig. 1). As a subgroup, immigrant/ descendant girls ( $n$ 40) had the highest deficiency prevalence; $80 \%$ had concentrations $\leq 50 \mathrm{nmol} / \mathrm{l}$ (Fig. 2). The proportion of immigrant/descendant children who were sampled in August/ September, October and November, respectively, did not differ from that of non-immigrant/descendant children $(P=0 \cdot 10)$, nor did the proportion of boys and girls $(P=0 \cdot 47)$.

\section{Determinants of 25-hydroxyvitamin D concentrations}

Analysis on determinants of vitamin D status comprised $n 724$ children, except for analyses on bicycling ( $n$ 624) and dietary vitamin D and Ca intake ( $n$ 681). No interaction effects were found between sex and puberty, sex and ethnicity, or sex and month of sampling ( $P=0.073, P=0.051$ and $P=0.429$, respectively), whereas an interaction effect between sex and immigrant/ descendant background was observed $(P=0.003)$. Consequently, the demographic model included age, proportion of days with intake of vitamin D-containing supplements, sex, ethnicity, immigrant/descendant background, puberty, month of sampling, parental education and the interaction between sex and immigrant/descendant background (Table 3).

In the subsequent analyses MVPA and outdoor walking between classrooms during school hours were found to be behavioural determinants of serum 25(OH)D (Table 3), whereas no associations were observed with obligatory outdoor recesses, BMI-for-age $z$ score, sedentary time, amount of bicycling, dietary vitamin $\mathrm{D}$ and $\mathrm{Ca}$ intake, and whole-blood EPA+DHA concentrations.

In the demographic model adjusted simultaneously for the two significant behavioural determinants, MVPA and outdoor walks between classrooms, serum 25(OH)D increased $0.06 \mathrm{nmol} / 1(95 \%$ CI $0.01,0.12 ; P=0.022) / \mathrm{min}$ per $\mathrm{d}$ in MVPA and $0.4 \mathrm{nmol} / 1(95 \% \mathrm{CI}$ $0 \cdot 1,0 \cdot 6 ; P=0 \cdot 003) / \mathrm{min}$ per week of walking outdoors between classrooms (Table 3). In this model, children sampled in November had a $-13.3 \mathrm{nmol} / 1(95 \% \mathrm{CI}-17 \cdot 7,-9 \cdot 1 ; P<0.001)$ lower serum 25(OH)D compared with those sampled in August/September (Table 3) and a $-8.1 \mathrm{nmol} / 1$ (95\% CI -12.6, -3.5; $P=0.001)$ lower $25(\mathrm{OH}) \mathrm{D}$ concentration compared with those sampled in October (data not shown). Also, children sampled in October had a $-5 \cdot 2 \mathrm{nmol} / \mathrm{l}(95 \% \mathrm{CI}-10 \cdot 1,-0 \cdot 4 ; P=0 \cdot 033)$ lower serum 25(OH)D

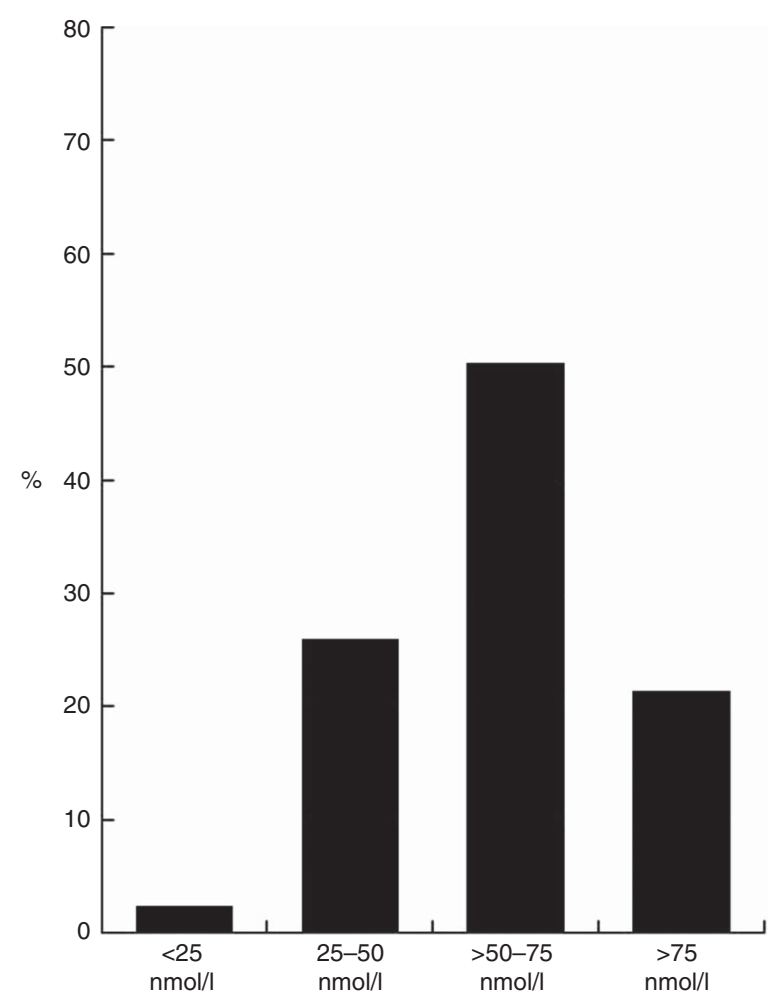

Fig. 1. Prevalence (\%) according to specific serum 25-hydroxyvitamin D $(25(\mathrm{OH}) \mathrm{D})$ cut-off levels in all 782 children. Unadjusted data. The cut-off levels are based on the European Society for Paediatric Gastroenterology, Hepatology and Nutrition recommendations where serum levels $>50 \mathrm{nmol} / \mathrm{l}$ indicate sufficiency ${ }^{(1)}$. A level $>75 \mathrm{nmol} / /$ indicates an alternative sufficiency level as suggested by others ${ }^{(6)}$.

compared with those sampled in August/September (Table 3). Increasing age, being a girl, being non-white and being immigrant/ descendant were also associated with lower serum 25(OH)D concentrations (Table 3). Children from households with a parental education level of at least a Master's degree ( $\geq 17$ years) were found to have a higher serum $25(\mathrm{OH}) \mathrm{D}$ level compared with children from households with parental level of lower secondary education ( $\leq 10$ years) 6.9 (95\% CI 1.0, 12.8 nmol/l; $P=0.021$ ) (Table 3 ), with vocational education $(5 \cdot 1 ; 95 \% \mathrm{CI} 2 \cdot 1,8.1 \mathrm{nmol} / 1 ; P=0.001)$, with short higher education ( $4.3 ; 95 \% \mathrm{CI} 0.2,8.4 \mathrm{nmol} / \mathrm{l} ; P=0.039)$ and with Bachelor's degree or equivalent ( $4.5 ; 95 \%$ CI 1.5, 7.6 nmol/1; $P=0.004)$ (data not shown). The $25(\mathrm{OH}) \mathrm{D}$ status in immigrant/ descendant boys was estimated to be $9 \cdot 4 \mathrm{nmol} / 1$ (95\% CI 2.2, 16.6; $P=0 \cdot 010)$ higher than in immigrant/descendant girls. In comparison, the difference between non-immigrant boys and girls was $3.3 \mathrm{nmol} / 1$ (95\% CI 0.7, 5.9; $P=0.012)$.

The categorical vitamin $\mathrm{D}$ supplements variable constructed for sub-analysis on the association between frequency of vitamin D-containing supplements intake and serum $25(\mathrm{OH}) \mathrm{D}$ included $n 693$ children who recorded dietary intake for all $7 \mathrm{~d}$ (Table 1). The sub-analysis with this categorical vitamin D supplements variable in the demographic model included $n 673$ children. Here, we found higher serum 25(OH)D concentrations in those children who took vitamin D-containing supplements 3, 4, 5, 6 and $7 \mathrm{~d} / 7 \mathrm{~d}$ compared with children who consumed supplements 0 out of $7 \mathrm{~d}(P<0.001$; Fig. 3). Serum 25(OH)D concentration was 
(a)

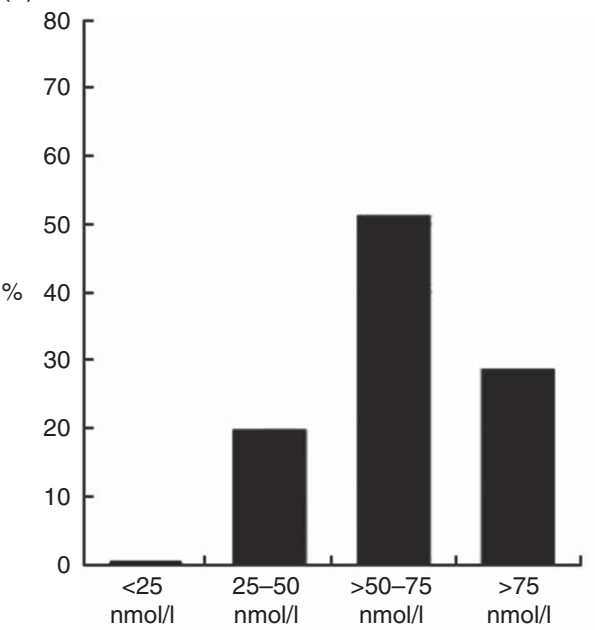

(c)

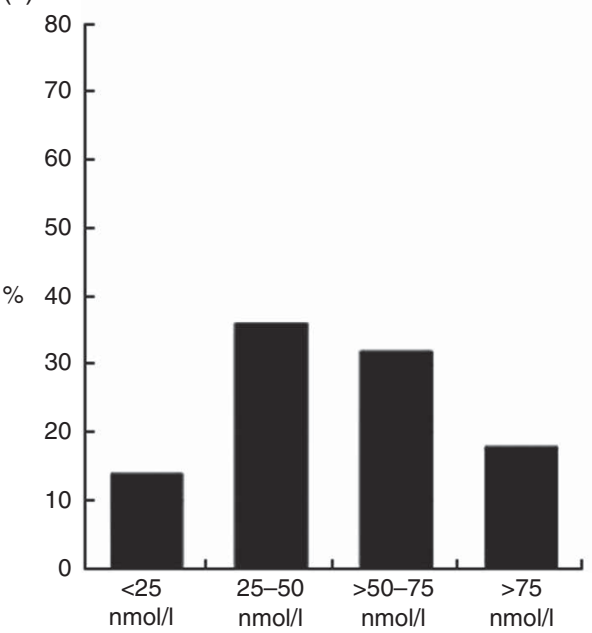

(b)

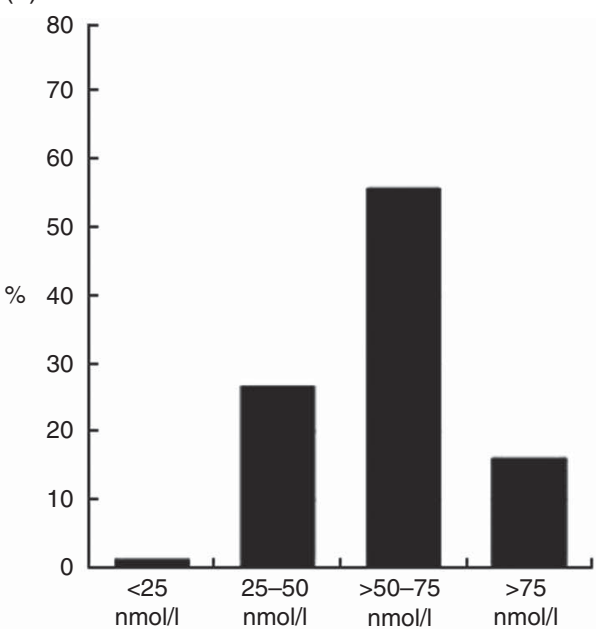

(d)

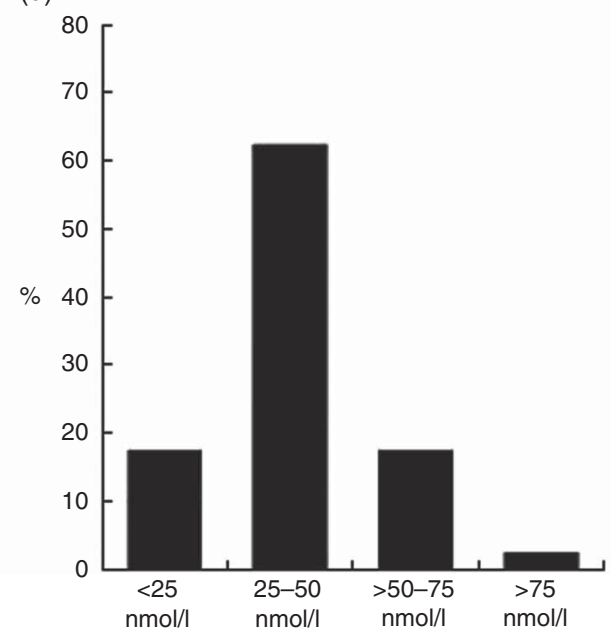

Fig. 2. Prevalence (\%) according to specific serum $25(\mathrm{OH}) \mathrm{D}$ cut-off levels in subgroups. Unadjusted data. Subgroups are according to sex and immigrant/descendant background. (a) Non-immigrant/descendant boys, $n$ 359; (b) non-immigrant/descendant girls, $n$ 333; (c) immigrant/descendant boys, $n 50$; (d) immigrant/descendant girls, $n$ 40. Cut-off levels are based on the European Society for Paediatric Gastroenterology, Hepatology and Nutrition recommendations where serum levels $>50 \mathrm{nmol} / /$ indicate sufficiency ${ }^{(1)}$. A level $>75 \mathrm{nmol} / \mathrm{l}$ indicates an alternative sufficiency level as suggested by others ${ }^{(6)}$.

found to be constant among children taking supplements for $0-2 \mathrm{~d} /$ $7 \mathrm{~d}$ as well as among children taking supplements for $3-7 \mathrm{~d} / 7 \mathrm{~d}$ $(P=0 \cdot 64)$. Consequently, the categorical supplements variable was collapsed into a dichotomous variable of $0-2 \mathrm{~d} / 7 \mathrm{~d}$ and $3-7 \mathrm{~d} / 7 \mathrm{~d}$, respectively. When this collapsed variable was included in the demographic model, intake of vitamin D-containing supplements for 3-7 d ( $n$ 282) was associated with an increase of $9.0 \mathrm{nmol} / \mathrm{l}$ (95\% CI 6.7, 11.2; P<0.001) as compared with intake for $0-2 \mathrm{~d} / 7 \mathrm{~d}$ ( $n$ 391). A comparable estimate was observed, $8.7 \mathrm{mmol} / \mathrm{l}$ (95\% CI $6 \cdot 4,11 \cdot 0 ; P<0 \cdot 001)$, when additionally adjusted for MVPA and outdoor walks.

\section{Discussion}

Approximately $70 \%$ of the school children in this cross-sectional study had serum $25(\mathrm{OH}) \mathrm{D}$ levels $>50 \mathrm{nmol} / \mathrm{l}$ during autumn months. Consequently, concentrations $\leq 50 \mathrm{nmol} / \mathrm{l}$ were observed in almost one-third of the children at the time of year when concentrations are expected to be close to the annual peak. Compared with studies conducted at similar latitudes and time of year, mean $25(\mathrm{OH}) \mathrm{D}$ status in the present study (approximately $61 \mathrm{nmol} / \mathrm{l})$ was fairly equal to that observed in 4-6-year-old Swedish children $\left(60 \mathrm{nmol} / 1 \text {, August-September, } 63^{\circ} \mathrm{N}\right)^{(24)}$ and 11-13-year-old Danish girls $(60 \cdot 3 \mathrm{nmol} / 1$, August-September, $\left.55.4^{\circ} \mathrm{N}\right)^{(16)}$. In contrast, mean $25(\mathrm{OH}) \mathrm{D}$ status in the present study was lower than in 4-18-year-old British children $(71.2 \mathrm{nmol} / \mathrm{l}$, June-November, $\left.50-59^{\circ} \mathrm{N}\right)^{(45)}$ and 8-year-old Swedish children $\left(82 \cdot 8 \mathrm{nmol} / 1 \text {, summer, } 57^{\circ} \mathrm{N}\right)^{(22)}$. Yet, between-study comparisons are problematic because of different methods of $25(\mathrm{OH}) \mathrm{D}$ analysis. Also, differences in, for example, fortification programmes between countries must be taken into account. Indeed, food fortification with vitamin $\mathrm{D}$ is neither mandated nor common in Denmark. On the basis of the well-established association between serum 25(OH)D and season at northern latitudes $^{(16,22,24,45-47)}$, the mean serum $25(\mathrm{OH}) \mathrm{D}$ concentration above sufficiency level in the present study matched the 


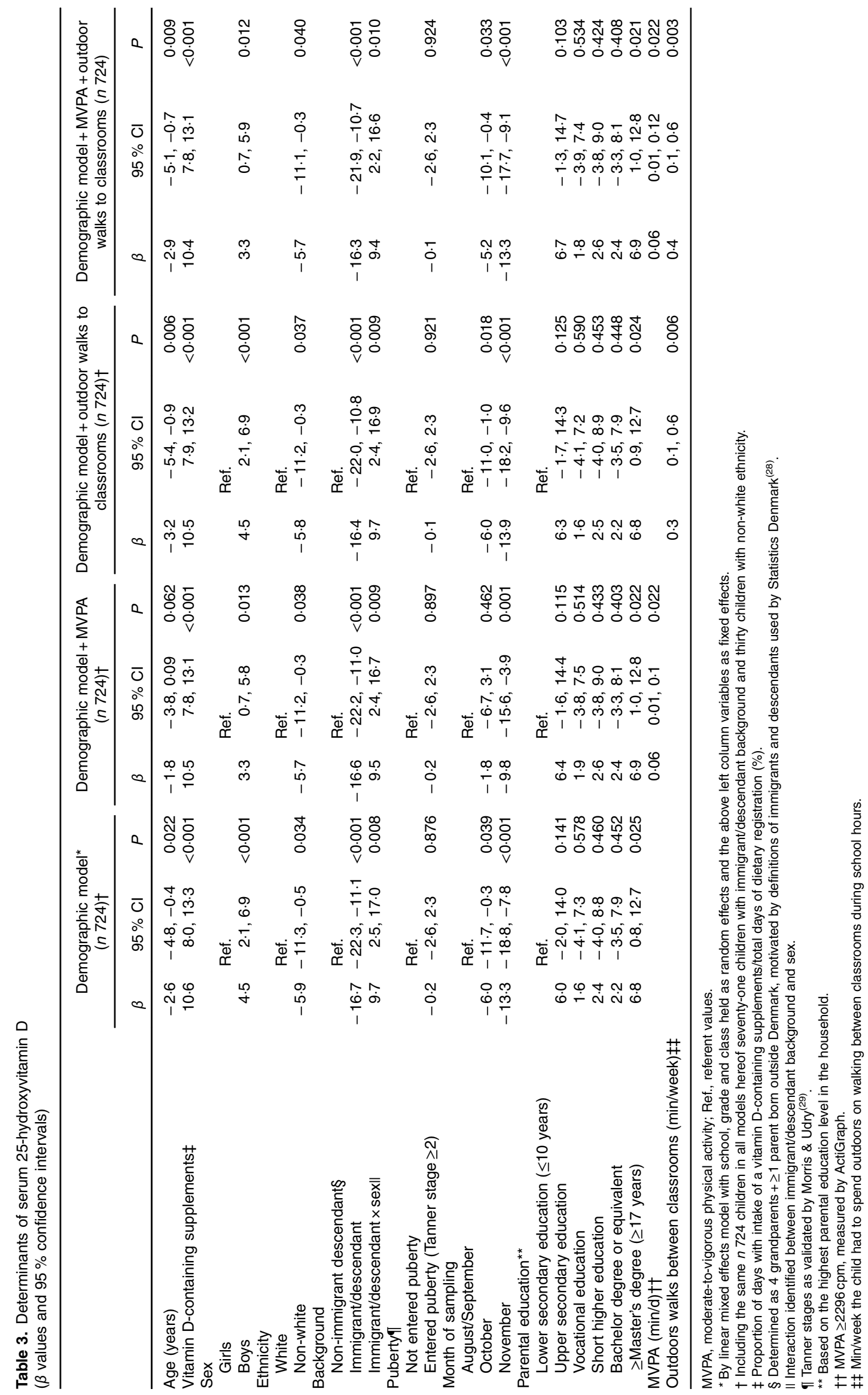




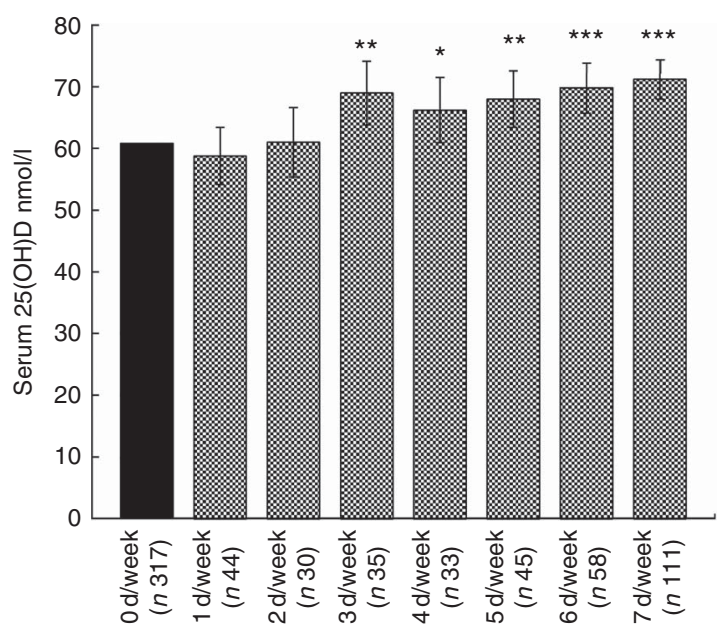

Fig. 3. Association between intake of vitamin D-containing supplements in $\mathrm{d} /$ week and serum 25-hydroxyvitamin $\mathrm{D}(25(\mathrm{OH}) \mathrm{D})$. Sub-analysis with the children who registered for all $7 \mathrm{~d} /$ week. Adjusted for age, sex, white ethnicity, immigrant/descendant background, month of sampling and parental education, $n$ 673. Statistical significance tested against reference: 0 days/week: ${ }^{*} P<0.05$, ${ }^{* *} P<0.01,{ }^{* * *} P<0.001$.

expectation that serum $25(\mathrm{OH}) \mathrm{D}$ peaks in summer/autumn. And the seasonal fluctuation was further reaffirmed in the present study by the lower vitamin D levels measured in November compared with October and August/September, and was consistent with the hypothesis of November being the first month in the 'vitamin D winter' at these latitudes. Yet, our results also demonstrated that $25(\mathrm{OH}) \mathrm{D}$ insufficiency is not to be perceived solely as a winter phenomenon. Indeed, it is of particular concern that $2.4 \%$ of the children had autumn 25(OH)D concentrations below $25 \mathrm{nmol} / \mathrm{l}$. As $25(\mathrm{OH}) \mathrm{D}$ concentrations are expected to decrease further during winter and early spring, these children are believed to be at risk for critically low winter status ${ }^{(16)}$. This result underlines the relevance of an evaluation of potential demographic and behavioural determinants of children's autumn vitamin D status. Indeed, although diverging cut-off levels for the optimal vitamin D level in children have been proposed and applied ${ }^{(6)}$, the $25 \mathrm{nmol} / \mathrm{l}$ threshold is established on the basis of its clinically observed association with rickets and osteomalacia ${ }^{(1)}$.

In the present study we did not find dietary intake to be associated with autumn serum $25(\mathrm{OH}) \mathrm{D}$ concentrations. This is consistent with other studies at similar latitudes with summer/ autumn data ${ }^{(16,45)}$, and underlines sunlight as the major source at this time of year. However, in line with other studies in children at northern latitudes ${ }^{(16,20,22,45)}$, we did find intake of vitamin D-containing supplements to be a strong determinant of serum $25(\mathrm{OH}) \mathrm{D}$. In our specific sub-analysis, we did not find any benefit in taking a vitamin D-containing supplement only 1 or $2 \mathrm{~d} / 7 \mathrm{~d}$ compared with $0 \mathrm{~d}$. Three days of vitamin D-containing supplementation per $7 \mathrm{~d}$ was associated with a notable increase of approximately $9 \mathrm{nmol} / \mathrm{l}$ and was found to be equally associated with autumn $25(\mathrm{OH}) \mathrm{D}$ concentrations as an intake 4, 5, 6 or $7 \mathrm{~d} / 7 \mathrm{~d}$. These are, to our knowledge, new levels of detail as most previous studies have looked at supplementation intake on a yes/no, and often all year-round basis ${ }^{(16,22,45)}$. Our findings underline supplements intake as an important determinant of vitamin D status, also observable at the time of year when sunlight is abundant, but only if intake is frequent enough.

Among the demographic variables, our study pointed to non-white ethnicity, immigrant/descendant background, girl sex, and particularly the combination of girl sex and immigrant/ descendant background as determinants of lower vitamin D status. The Danish authorities have identified certain population groups to be at risk for vitamin $\mathrm{D}$ deficiency. These include children $0-2$ years of age, individuals with dark skin complexion, individuals who dress to cover most of the body during summer, individuals who rarely go outdoors and individuals who avoid sunlight ${ }^{(48)}$. In addition to these officially identified groups, our results imply a need for also focusing on girls, children with an immigrant/descendant background, and older children such as adolescents and teenagers.

Other studies have found similar associations between immigrant background and low vitamin D status ${ }^{(22,23,25,49)}$, but definitions of immigrant background vary, as does the suggested explanations for the association ${ }^{(50)}$. In the present study, factors such as parental education, vitamin D supplementation, BMI, puberty stage, physical activity, screen time and dietary intake were all excluded as potential explanations of the association, and none of the children wore veils. Children from Turkey, the Middle East, Pakistan and India were categorised as white, and it cannot be ruled out that these children had darker skin tones than the white non-immigrant/descendant children. Yet, this does not explain that there was a difference between immigrant/ descendant boys and girls. Interestingly, studies in Caucasian adolescent girls and women at similar latitudes as the present study have previously observed good correlation between usual sun habits and summer vitamin D status ${ }^{(16)}$. We therefore speculate that behavioural factors such as time spent outside, area of skin exposed and overall sun-seeking behaviour, which was unfortunately not measured in the present study, may be culturally influenced, and different in children, particularly in girls, with an immigrant/descendant background ${ }^{51,52)}$. Unfortunately we obtained dietary recordings from only $64 \%$ of the immigrant/ descendant children compared with $90 \%$ of the non-immigrant children. It is therefore also possible that actual differences in dietary vitamin $\mathrm{D}$ intake between immigrant and non-immigrant children are substantially larger than captured in this study.

The decrease in serum $25(\mathrm{OH}) \mathrm{D}$ with age in childhood has been observed in other studies ${ }^{(45,46,49)}$, although not consistently ${ }^{(20,22)}$. Our finding of higher status in boys compared with girls was not seen in previous studies conducted at similar northern latitudes $(22,24,45)$. Varying behavioural patterns may likewise be relevant to consider in regard to these observed age and sex differences in serum 25(OH)D. Interestingly, an American study in children and adolescents has, for example, shown that 13-19-year-olds spend the least time outdoors compared with any other age group, and that teenage girls decreased their outdoor activities more dramatically than did teenage boys ${ }^{(53)}$. Similar findings occurred in a UK population comparing 9-10-year-olds and 14-15-year-olds ${ }^{(54)}$. We hypothesise that the association between age and serum 25(OH)D was mediated by such age-determined behavioural changes in outdoor activity in the present study, particularly because the association with age disappeared when MVPA was added to the demographic model. 
Indeed, we speculate that MVPA may be positively associated with outdoor activity, but evidence on the nature of this association is needed.

Our results indicated that age was not a contributor to serum 25(OH)D status when MVPA was included in the demographic model, whereas age remained significant when outdoor walks was included. In our sample outdoor walks between classrooms was higher among fourth graders compared with third graders $(P<0.001)$. Hence, correlations and associations between these variables along with potential residual confounding are relevant considerations for interpretation of these outcomes.

To our knowledge the present study is the first to explicitly investigate the association between children's vitamin D status and outdoor activity during school hours. Interestingly, and consistent with the hypothesis that only a few minutes of daily sun exposure is adequate to cover the vitamin D requirement, we found that even a few weekly minutes of outdoor walking between classrooms during school hours appeared to have a strong impact on the vitamin D status of children in autumn. This is also in accordance with the fact that school hours are placed at the time of day when sunshine is brightest. Contrary to outdoor walking between classrooms, obligatory outdoor recesses did not predict serum $25(\mathrm{OH}) \mathrm{D}$ concentrations. This was surprising. However, we speculate that children may spontaneously prefer to go outdoors during recesses at this time of year even if they are not obligated to do so by school policy, particularly as autumn weather is usually good in Denmark and all schools have outdoor facilities for children during recesses. Consequently, this 'voluntary factor' is likely to have affected the validity of the outdoor recess variable and might explain why an association was not observed even though it scientifically appears a likely determinant. Consequently, outdoor walks between classrooms is speculated to be a more valid measure of outdoor activity as it holds a clear non-voluntary behavioural necessity in order to get to class, and it proved robustly and highly associated with serum 25(OH)D. Inexpensive and easily applicable, brief intervals of outdoor activity during school hours may be worth investigating further as a way to safely and effectively improve autumn vitamin D status in children, especially in older children.

The DiaSorin LIAISON assay applied to measure 25(OH)D in the current study has been shown to be the superior among automated immunoassays ${ }^{(55)}$. It has, however, previously been found to report lower $25(\mathrm{OH}) \mathrm{D}$ concentrations compared with the liquid chromatography-tandem spectrometry method considered the golden standard ${ }^{(56)}$. A risk of overestimation of low vitamin D status therefore exists in our study. The 2010 DEQAS survey found DiaSorin LIAISON to have a mean deviation from the all-laboratory-trimmed mean of minus $4-5 \%{ }^{(57)}$. Applying this potential $5 \%$ underestimation to our results would increase mean serum $25(\mathrm{OH}) \mathrm{D}$ level for the total study population by $3 \mathrm{nmol} / \mathrm{l}$ to 63.8 (sD 19.7) $\mathrm{nmol} / \mathrm{l}$. As a result $24.4 \%$ of the children would then be categorised as insufficient and $1.9 \%$ as deficient compared with the respectively reported 28.4 and $2.4 \%$, which is still a substantial part of the children. Also, DiaSorin LIAISON has been suggested to have a mean bias of only $0.5 \mathrm{nmol} / 1$ compared with the liquid chromatography-tandem spectrometry method ${ }^{(55)}$ - that is, a lesser underestimation than the one presented here.
The descriptive nature of our cross-sectional study naturally limits the ability to draw conclusions about causality. In view of the explorative nature of our study we have opted for reporting $P$ values unadjusted for multiple comparisons in combination with cautious interpretation of results, which need to be reinforced through similar trends found in different analyses. The robust findings throughout the adjustments and models in Table 3 do not, however, suggest random findings. The risk of collinearity was addressed by testing each behavioural factor one at a time in the same basic demographic model. This approach also ensured transparency in the analyses. Still, although we were able to adjust for important potential confounders such as sex, age, month of sampling, parental education, supplemental intake, immigrant/ descendant background and non-white ethnicity, there is always a risk of residual confounding in a cross-sectional study like the present. Records of direct sun exposure and overall behaviour regarding sun exposure would have been a strength, as factors such as sunny vacations and outdoor activities after school are possible residual confounders of the results.

There are several strengths to the present study. The extent and validity of determinants investigated, such as $\geq 4$-day webbased dietary recordings and validated objective accelerometry measurements of physical activity along with the explorative inclusion of innovative determinants regarding outdoor activity during school hours, makes this study unique. In addition, data were collected at the time of year when behavioural factors are indeed speculated to be of particular importance at this latitude. Importantly, the study population was substantially larger than in previous Scandinavian studies, and a specific goal was representativeness of the study sample. Recruitment was conducted from nine geographically and demographically varying areas. The enrolment rate was high at $82 \%$, and, although the proportion of non-white ethnicity in our sample might appear small, it is considered fairly representative of the Danish population as a whole. All parental education levels were present, and the $11.5 \%$ of children characterised as immigrants/ descendants corresponded well with the $10 \cdot 1 \%$ of immigrants/ descendants reported in the general Danish population ${ }^{(58)}$. Also, distribution of country of origin of the included immigrant/descendant children was in accordance with that found in the general Danish population ${ }^{(58)}$. Similarly, the prevalence of dietary supplement users in our study population, $55 \%$ among girls and $50 \%$ among boys, appears to mirror well that of the general population, although our variable included vitamin D-containing supplements only, hereunder also multivitamins. Indeed, in national surveys, 46 and $55 \%$ of 11-14-year-old Danish girls and boys and 60 and $51 \%$ of adult Danish women and men reported taking dietary supplements ${ }^{(59,60)}$. All together, this indeed indicates a high degree of representativeness in our study.

In conclusion, almost one-third of the 8-11-year-old Danish children in this large representative study population did not reach the recommended 25(OH)D sufficiency level of $>50 \mathrm{nmol} / \mathrm{l}$ during autumn. This raises concern as status is expected to drop further during winter, and indicates that vitamin $\mathrm{D}$ deficiency might not be regarded solely as a winter phenomenon in children at northern latitudes. Older age, female sex, non-white ethnicity and immigrant/descendant background, particularly in females, are all 
factors associated with lower vitamin D status and therefore relevant when evaluating the determinants of vitamin D status in children. Frequent intake of vitamin D-containing supplements in autumn was an observable positive determinant of autumn vitamin D status in the children. Interestingly, increased MVPA and brief outdoor walks between classrooms during school hours were also found to be positive behavioural determinants of vitamin D status. In contrast, obligatory outdoor recess was not. Yet, the validity of this variable was potentially affected by children who chose to go outdoors during recesses even when it was not obligatory by school policy. Hence, more valid data on outdoor activity during recesses are needed in future studies, and these potential behavioural initiatives to improve autumn vitamin D status in children should be investigated further in randomised trials.

\section{Acknowledgements}

The authors greatly thank all the children and their families, the school management, the teachers and all other staff at the schools, as well as the OPUS Study team (kitchen staff, dietitians, laboratory technicians and students), for their participation and contribution to the study.

The OPUS project was supported by a grant from the Nordea Foundation (grant no. 02-2010-0389). Danæg A/S, Naturmælk, Lantmännen A/S, Skærtoft Mølle A/S, Kartoffelpartnerskabet, AkzoNobel Danmark, Gloria Mundi and Rose Poultry A/S provided foods in kind for the study. Sources of funding and donation had no role in the trial design; collection, analysis, or interpretation of data; or decision to publish.

C. M., K. F. M., A. A., I. T., L. B. S., S.-M. D., C. T. D. and R. A. P. designed research; R. A., M. F. H., L. B. S., S.-M. D., C. T. D., L. K. and R. A. P. conducted research; C. R. and R. A. P. analysed the data; H. K. provided acquisition of data; R. A. P. wrote the paper; R. A. P. had primary responsibility for the final content.

R. A. P. none; C. T. D. none; S.-M. D. none; L. B. S. none; M. F. H. none; R. A. none; I. T. none; L. K. none; H. K. none; C. R. none; A. A. is consultant/member of advisory boards for the Dutch Beer Knowledge Institute, the Netherlands; Global Dairy Platform, USA; Jenny Craig, USA; McCain Foods Ltd, USA; McDonald's, USA; Gerson Lehrman Group, USA ( $a d$ boc consultant for clients). He is recipient of honoraria and travel grants as speaker for a wide range of Danish and international concerns. He has conducted research funded by a number of organisations with interests in the food production and marketing sector; K. F. M. none; C. M. none.

\section{References}

1. Braegger C, Campoy C, Colomb V, et al. (2013) Vitamin D in the healthy paediatric population: a position paper by the ESPGHAN Committee on nutrition. J Pediatr Gastroenterol Nutr 56, 692-701.

2. Bouillon R, Van Cromphaut S \& Carmeliet G (2003) Intestinal calcium absorption: molecular vitamin $\mathrm{D}$ mediated mechanisms. J Cell Biochem 88, 332-339.

3. Christakos S (2011) Mechanism of action of 1,25-dihydroxyvitamin $\mathrm{D}_{3}$ on intestinal calcium absorption. Rev Endocr Metab Disord 13, 39-44.

4. Molgaard C, Thomsen BL \& Michaelsen KF (1999) Whole body bone mineral accretion in healthy children and adolescents. Arch Dis Child 81, 10-15.
5. Holick MF (2004) Sunlight and vitamin D for bone health and prevention of autoimmune diseases, cancers, and cardiovascular disease. Am J Clin Nutr 80, Suppl, 1678S-1688S.

6. Henry HL, Bouillon R, Norman AW, et al. (2010) 14th Vitamin D Workshop consensus on vitamin D nutritional guidelines. J Steroid Biochem Mol Biol 121, 4-6.

7. Wharton B \& Bishop N (2003) Rickets. Lancet 362, 1389-1400.

8. Beck-Nielsen SS, Jensen TK, Gram J, et al. (2009) Nutritional rickets in Denmark: a retrospective review of children's medical records from 1985 to 2005. Eur J Pediatr 168, 941-949.

9. Zipitis CS \& Akobeng AK (2008) Vitamin D supplementation in early childhood and risk of type 1 diabetes: a systematic review and meta-analysis. Arch Dis Child 93, 512-517.

10. Scragg R (2011) Vitamin D and public health: an overview of recent research on common diseases and mortality in adulthood. Public Health Nutr 14, 1515-1532.

11. National Food Institute-Technical University of Denmark (DTU). (2009) Danish food composition databank-ed. 7.01. http://www. foodcomp.dk/v7/fcdb_foodnutrlist.asp?CompId=0023 （accessed February 2012)

12. Holick MF (2002) Vitamin D: the underappreciated D-lightful hormone that is important for skeletal and cellular health. Curr Opin Endocrinol Diabetes 9, 87-98.

13. Webb AR, Kline L \& Holick MF (1988) Influence of season and latitude on the cutaneous synthesis of vitamin $\mathrm{D}_{3}$ : exposure to winter sunlight in Boston and Edmonton will not promote vitamin $\mathrm{D}_{3}$ synthesis in human skin. J Clin Endocrinol Metab 67, 373-378.

14. Kimlin MG (2008) Geographic location and vitamin D synthesis. Mol Aspects Med 29, 453-461.

15. Engelsen O (2010) The relationship between ultraviolet radiation exposure and vitamin D status. Nutrients 2 , 482-495.

16. Andersen R, Brot C, Jakobsen J, et al. (2013) Seasonal changes in vitamin D status among Danish adolescent girls and elderly women: the influence of sun exposure and vitamin D intake. Eur J Clin Nutr 67, 270-274.

17. Astner S \& Anderson RR (2004) Skin phototypes 2003.J Invest Dermatol 122, xxx-xxxi.

18. Holick MF, MacLaughlin JA \& Doppelt SH (1981) Regulation of cutaneous previtamin $\mathrm{D}_{3}$ photosynthesis in man: skin pigment is not an essential regulator. Science 211, 590-593.

19. Chen TC, Chimeh F, Lu Z, et al. (2007) Factors that influence the cutaneous synthesis and dietary sources of vitamin D. Arch Biochem Biophys 460, 213-217.

20. Andersen R, Molgaard C, Skovgaard LT, et al. (2005) Teenage girls and elderly women living in northern Europe have low winter vitamin D status. Eur J Clin Nutr 59, 533-541.

21. Holvik K, Brunvand L, Brustad M, et al. (2008) Vitamin D status in the Norwegian population. In Solar Radiation and Human Health, pp. 216-228. [E Bjertnes, editor]. Oslo: The Norwegian Academy of Science and Letters.

22. Eriksson S \& Strandvik B (2010) Vitamin D status in healthy children in Sweden still satisfactory. Changed supplementation and new knowledge motivation for further studies. Lakartidningen 107, 2474-2477 (English abstract).

23. Glerup H, Rytter L, Mortensen L, et al. (2004) Vitamin D deficiency among immigrant children in Denmark. Eur $J$ Pediatr 163, 272-273.

24. Ohlund I, Silfverdal SA, Hernell O, et al. (2013) Serum 25-hydroxyvitamin D levels in preschool-age children in northern Sweden are inadequate after summer and diminish further during winter. J Pediatr Gastroenterol Nutr 56, 551-555.

25. Andersen R, Molgaard C, Skovgaard LT, et al. (2008) Pakistani immigrant children and adults in Denmark have severely low vitamin D status. Eur J Clin Nutr 62, 625-634.

26. Damsgaard CT, Dalskov SM, Petersen RA, et al. (2012) Design of the OPUS School Meal Study: a randomised controlled trial 
assessing the impact of serving school meals based on the New Nordic Diet. Scand J Public Health 40, 693-703.

27. Statistics Denmark (2009, 2010) StatBank Denmark: income, consumption and prices. INDKF7 2009 and INDKF11 2010. Copenhagen: Statistics Denmark. www.statistikbanken.dk (accessed February 2012).

28. Statistics Denmark (2012) Immigrants and their descendants. Available at: www.dst.dk/en/Statistik/dokumentation/Declarations/ immigrants-and-their-descendants.aspx (accessed February 2012).

29. Morris NM \& Udry JR (1980) Validation of a self-administered instrument to assess stage of adolescent development. $J$ Youth Adolesc 9, 271

30. Biltoft-Jensen A, Trolle E, Christensen T, et al. (2014) WebDASC: a web-based dietary assessment software for 8-11-year-old Danish children. J Hum Nutr Diet 27, Suppl. 1, 43-53.

31. Biltoft-Jensen A, Hjorth MF, Trolle E, et al. (2013) Comparison of estimated energy intake using Web-based Dietary Assessment Software with accelerometer-determined energy expenditure in children. Food Nutr Res 57, 10.3402/fnr.v57i0.21434.

32. Biltoft-Jensen A, Bysted A, Trolle E, et al. (2013) Evaluation of Web-based Dietary Assessment Software for Children: comparing reported fruit, juice and vegetable intakes with plasma carotenoid concentration and school lunch observations. Br J Nutr 110, 186-195.

33. Pedersen A, Fagt S, Groth M, et al. (2010) Dietary Habits in Denmark 2003-2008. Søborg: Division of Nutrition, National Food Institute, Technical University Denmark, DTU fødevareinstituttet (in Danish).

34. Henry CJ (2005) Basal metabolic rate studies in humans: measurement and development of new equations. Public Health Nutr 8, 1133-1152.

35. Black AE (2000) The sensitivity and specificity of the Goldberg cut-off for EI:BMR for identifying diet reports of poor validity. Eur J Clin Nutr 54, 395-404.

36. Hjorth MF, Chaput JP, Michaelsen K, et al. (2013) Seasonal variation in objectively measured physical activity, sedentary time, cardio-respiratory fitness and sleep duration among 8-11 year-old Danish children: a repeated-measures study. $B M C$ Public Health 13, 808.

37. World Health Organization (2012) WHO AnthroPlus Macros for STATA. http://www.who.int/growthref/tools/en/ (accessed February 2012)

38. Carter GD, Berry JL, Gunter E, et al. (2010) Proficiency testing of 25-hydroxyvitamin D (25-OHD) assays. J Steroid Biochem Mol Biol 121, 176-179.

39. Armstrong JM, Metherel AH \& Stark KD (2008) Direct microwave transesterification of fingertip prick blood samples for fatty acid determinations. Lipids 43, 187-196.

40. Damsgaard CT, Stark KD, Hjorth MF, et al. (2013) n-3 PUFA status in school children is associated with beneficial lipid profile, reduced physical activity and increased blood pressure in boys. Br J Nutr 110, 1304-1312.

41. Cole TJ, Flegal KM, Nicholls D, et al. (2007) Body mass index cut offs to define thinness in children and adolescents: international survey. BMJ 335, 194.

42. Cole TJ, Bellizzi MC, Flegal KM, et al. (2000) Establishing a standard definition for child overweight and obesity worldwide: international survey. BMJ 320, 1240-1243.

43. Nordic Council of Ministers (2004) Nordic Nutrition Recommendations 2004. Copenhagen, Denmark: Norden.
44. Nordic Council of Ministers (2012/2013) Nordic nutrition recommendations 2012 - main conclusions of the NNR 2012. http://www.norden.org/en/theme/nordic-nutrition-recommen dation/main-conclusions-of-the-nnr-2012 (accessed October 2012).

45. Absoud M, Cummins C, Lim MJ, et al. (2011) Prevalence and predictors of vitamin D insufficiency in children: a Great Britain population based study. PLOS ONE 6, e22179.

46. Tolppanen AM, Fraser A, Fraser WD, et al. (2012) Risk factors for variation in 25-hydroxyvitamin $\mathrm{D}_{3}$ and $\mathrm{D}_{2}$ concentrations and vitamin D deficiency in children. J Clin Endocrinol Metab 97, 1202-1210.

47. Poskitt EM, Cole TJ \& Lawson DE (1979) Diet, sunlight, and 25-hydroxy vitamin D in healthy children and adults. Br Med J 1, 221-223.

48. National Board of Health, Denmark (2010) Oversigt over D-vitamin anbefalinger (Outline of vitamin D recommendations). http://sundhedsstyrelsen.dk/da/sundhed/ernaering/ /media/ 52BFED5C0E2C44C6A920DEC159611620.ashx (accessed February 2012) (in Danish)

49. Hintzpeter B, Scheidt-Nave C, Muller MJ, et al. (2008) Higher prevalence of vitamin $\mathrm{D}$ deficiency is associated with immigrant background among children and adolescents in Germany. J Nutr 138, $1482-1490$

50. Mygind A, Traulsen JM, Norgaard LS, et al. (2011) The ambiguity of ethnicity as risk factor of vitamin D deficiency - a case study of Danish vitamin D policy documents. Health Policy 102, 56-63.

51. Knoss R, Halsey LG \& Reeves S (2012) Ethnic dress, vitamin D intake, and calcaneal bone health in young women in the United Kingdom. J Clin Densitom 15, 250-254.

52. Webb AR (2006) Who, what, where and when-influences on cutaneous vitamin D synthesis. Prog Biophys Mol Biol 92, $17-25$.

53. Godar DE (2001) UV doses of American children and adolescents. Photochem Photobiol 74, 787-793.

54. Diffey BL, Gibson CJ, Haylock R, et al. (1996) Outdoor ultraviolet exposure of children and adolescents. $\mathrm{Br} J$ Dermatol 134, 1030-1034.

55. Farrell CJ, Martin S, McWhinney B, et al. (2012) State-of-the-art vitamin D assays: a comparison of automated immunoassays with liquid chromatography-tandem mass spectrometry methods. Clin Chem 58, 531-542.

56. de Koning L, Al-Turkmani MR, Berg AH, et al. (2013) Variation in clinical vitamin D status by DiaSorin Liaison and LC-MS/MS in the presence of elevated $25-\mathrm{OH}$ vitamin $\mathrm{D}_{2}$. Clin Chim Acta $\mathbf{4 1 5}, 54-58$.

57. Carter GD (2011) Accuracy of 25-hydroxyvitamin D assays: confronting the issues. Curr Drug Targets 12, 19-28.

58. Statistics Denmark (2012) Indvandrere $i$ Danmark 2011 (Immigrants in Denmark 2011). http://www.dst.dk/pukora/ epub/upload/16209/indv.pdf (accessed February 2012).

59. Gille M, Biltoft-Jensen A, Hartkopp H, et al. (2010) Brug Af Kosttilskud Blandt Unge Danskere-Og Sammenhaeng Med Noeringsstofindtag, Kostkvalitet Og Livsstilsfaktorer no. 1. udgave (Use of Dietary Supplements among Danish Adolescents - and Association with Nutrient Intake, Diet Quality, and Lifestyle Factors). Søborg: DTU Fødevareinstituttet.

60. Tetens I, Biltoft-Jensen A, Spagner C, et al. (2011) Intake of micronutrients among Danish adult users and non-users of dietary supplements. Food Nutr Res 55, 7153. 